\title{
Elementary Analysis of Petroleum Distillates by GC-AED: Validation and Application to the Calculation of Distillation Profile Properties
}

\author{
F. Baco' ${ }^{1}$ A. Quignard' and R. Szymanski² \\ 1 Institut français du pétrole, CEDI René Navarre, BP 3, 69390, Vernaison - France \\ 2 Institut français du pétrole, 1 et 4, avenue du Bois-Préau, 92852, Rueil-Malmaison Cedex - France \\ e-mail: franck.baco@ifp.fr
}

\begin{abstract}
Résumé - Analyse élémentaire des distillats pétroliers par couplage GC-AED : validation et application au calcul de propriétés en profil de distillation - Cet article décrit la mise au point de l'analyse élémentaire en profil de distillation des coupes pétrolières par couplage chromatographie en phase gazeuse-détection par émission atomique (GC-AED) et montre les perspectives d'application à la caractérisation de distillats moyens d'une information jusqu'alors inédite en routine. Les performances de l'ensemble analytique utilisé ont été étudiées pour l'analyse du carbone, de l'hydrogène, du soufre et de l'azote. La distillation simulée, analyse par chromatographie en phase gazeuse qui permet de déterminer le pourcentage poids de matière distillée en fonction du point d'ébullition des coupes pétrolières, a été adaptée sur le couplage GC-AED. On a développé une méthode qui donne accès à trois types d'information : composition élémentaire globale, distillation simulée et composition élémentaire en profil de distillation, c'est-à-dire par tranche (\%) de produit distillé. L'analyse des distillats atmosphériques a été évaluée en termes de fidélité et de justesse pour ces divers types d'information. La validation a été réalisée notamment par comparaison avec les résultats obtenus à l'aide de méthodes d'analyse de référence, sur des coupes de distillation préparative d'échantillons représentatifs. L'application du GC-AED à la caractérisation des distillats est discutée, en particulier à des fins de classement et pour la prédiction de propriétés pétrolières en profil de distillation. L’indice de cétane des gazoles a été pris comme exemple pour illustrer cette dernière application.
\end{abstract}

Mots-clés : analyse, GC-AED, distillation simulée, distillats, caractérisation, profils, propriétés, corrélation.

\begin{abstract}
Elementary Analysis of Petroleum Distillates by GC-AED: Validation and Application to the Calculation of Distillation Profile Properties - This article describes the development of elementary analysis in the distillation profile of petroleum cuts by gas phase chromatography-atomic emission detection (GC-AED) coupling and shows the application perspectives to characterisation of middle distillates of a piece of information unheard of until now on a routine basis. The performances of the analytical assembly used have been studied for carbon, hydrogen, sulphur and nitrogen analysis. Simulated distillation, a gas phase chromatography analysis which enables determining the weight percentage of distilled matter in relation to the boiling point of petroleum cuts, has been adapted to GC-AED coupling. We have developed a method giving access to three types of information: global elementary composition, simulated distillation and elementary composition in distillation profile, i.e. by fraction (\%) of the distilled product. The analysis of the atmospheric distillates has been assessed in terms of precision and bias for these various types of information. The validation was carried out notably
\end{abstract}


by comparison with the results obtained using reference analytical methods, on preparative distillation cuts of representative samples. The application of GC-AED to characterisation of distillates is discussed, in particular for classification purposes and for predicting petroleum properties in the distillation profile. The cetane number of gas oils was taken as an example to illustrate the latter application.

Keywords: analysis, GC-AED, simulated distillation, distillates, characterisation, profile, properties, correlation.

\section{INTRODUCTION}

Detailed analysis of the constituents of a petroleum cut by a simple and fast method such as gas phase chromatography (GC) is possible today only on cuts whose final boiling point is lower than $200^{\circ} \mathrm{C}$. The analysis of the composition of higher final boiling point cuts requires a complex methodology based on a set of analytical techniques. A conventional pattern consists for instance of a fractionating operation into group-types (saturated, aromatic compounds, etc.) by liquid chromatography, followed by mass spectrometry and nuclear magnetic resonance analyses. Characterisation becomes more complex and more inaccurate as the cuts become heavier ${ }^{1}$. At development level, it would prove useful to have simple and quantitative analytical tools, sufficiently explanatory to establish process relevant property/structure relationships. Coupling separation techniques (gas, liquid, let alone super-critical phase chromatography) and spectroscopic techniques (mass spectrometry, specific $S, N$, etc. detectors) seems a promising path.

In this context, our objective was to set up an elementary analysis of petroleum distillates by gas phase chromatographyatomic emission detection (GC-AED) coupling and to assess the relevancy of the technique. Simulated distillation, a gas phase chromatography analysis which enables determining the weight percentage of distilled matter in relation to the boiling point of petroleum cuts, has been adapted to GC-AED coupling in order to give access to elementary composition (C, $\mathrm{H}, \mathrm{S}$ ) in distillation profile, a piece of information unheard of until now on a routine basis. Indeed, this profile information could only be obtained, until now, after distilling the product into narrow cuts and analysing the different cuts using conventional elementary analytical methods. In this article, we shall present the results of analytical validation of the GCAED method as well as two examples of application taking advantage of the new information provided: classification of distillates of various origins and prediction of global properties and in distillation profile. We have focussed more especially on the prediction of the cetane number of gas oils.

\section{EXPERIMENTAL PART}

\subsection{Description of the GC-AED Analytical Chain}

The coupling used consists of an atomic emission detector AED HP 5921A and of a gas phase chromatograph HP 5890A

(1) This lime consuming and complet approach may only be used on basic research
Series II fitted with an "on-column"-type injector (direct injection of the product into the column without any flux division) and with an automatic sample changer HP 7673A. An automatic station HP Controller 382 controls the assembly. The GC-AED software (Chemstation GC-MS-AED) runs in pascal language. The vector gas of the chromatograph, which is also the plasmagenetic gas, is high purity helium.

Complete descriptions of the various components of the instrumentation have been presented in various works [1-5]. The operating principle of the assembly is summed up thereunder and a general coupling diagram is presented at Figure 1.

The sample is injected using an automatic sample changer into the chromatograph in an "on-column"-type operation. The molecules constituing the petroleum product are separated in relation to their boiling temperatures by a capillary column, in order to be detected at a later stage by a plasma atomic emission detector. Inside the detector, helium plasma is generated in a discharge tube using a microwave resonance cavity. The chromatograph is coupled to the microwave plasma by a heated transfer line that extends the chromatography column directly inside the discharge tube. The extremity of the column enters the cavity. The chromatographed effluents are fragmented into atoms excited by high-energy plasma. The atoms, when de-energising, emit an atomic emission spectrum that is transmitted to a spectrophotometer through a window provided in a chamber in the axis of the plasma. The emitted spectrum is separated into characteristic wavelengths by a holographic network and focussed onto a diode bar detector.

\subsection{Characteristics of the Detector for C-H-S-N Elementary Analysis}

Optimisation of the experimental conditions for distillate analysis calls for in-depth knowledge of the response of the atomic emission detector for $\mathrm{C}, \mathrm{H}, \mathrm{S}$ and elementary analysis. We shall present here the main results, for more detail, please refer to [5].

The study conducted on model compounds representative of the chemical structure present in distillates (paraffins, aromatic compounds, different structures of sulphur and nitrogen compounds), has enabled us determining the performances of the detector for $\mathrm{C}^{496 \mathrm{~nm}}, \mathrm{H}^{486 \mathrm{~nm}}, \mathrm{~S}^{181 \mathrm{~nm}}$ and $\mathrm{N}^{174 \mathrm{~nm}}$ emission rays, in terms of sensitivity, detection limit, linearity field and influence of the structure of compounds. 


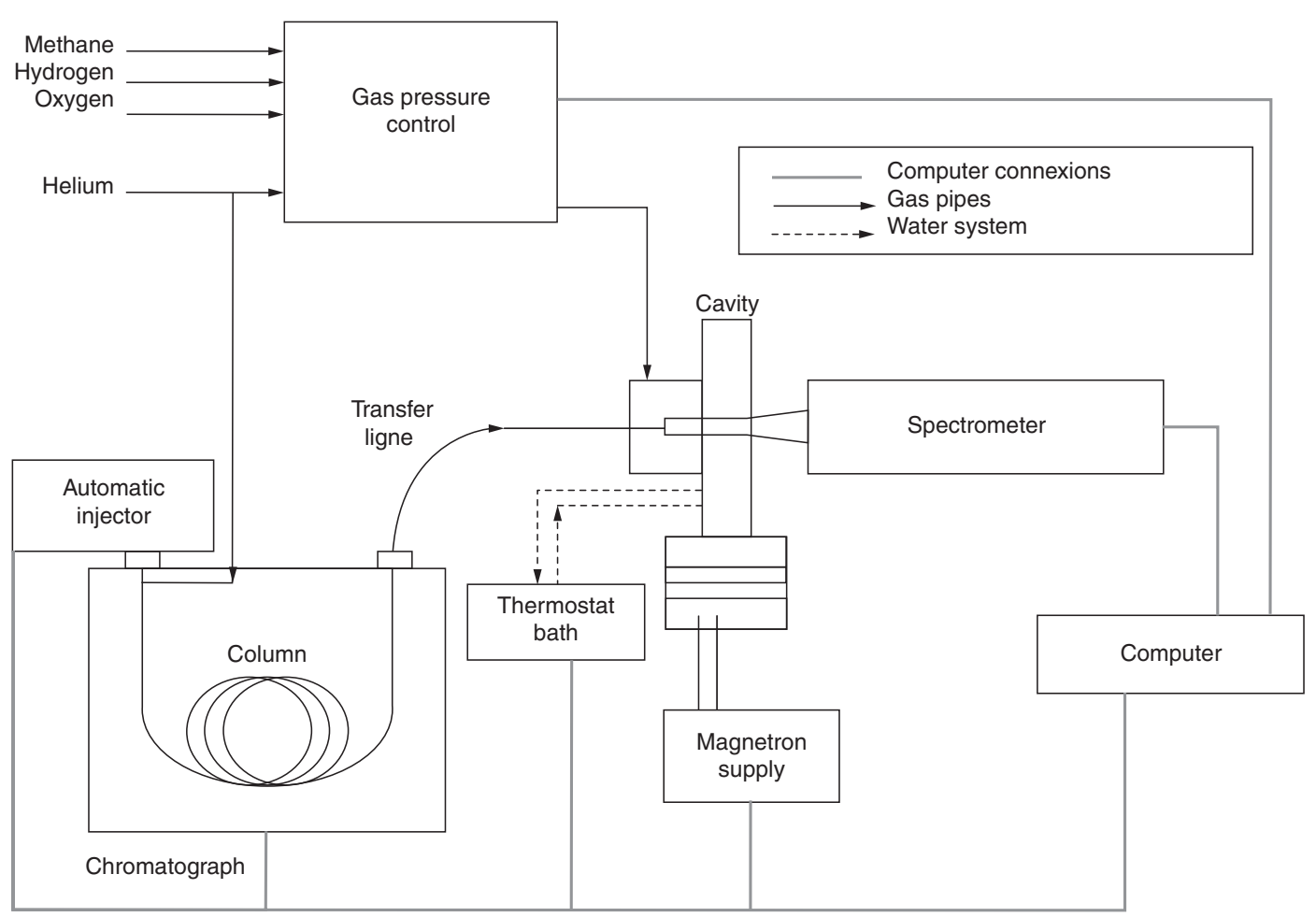

Figure 1

General overview of the GC-AED coupling.

The decisive results concerning the application contemplated, presented at Table 1, have shown that the atomic emission detector exhibits:

- good sensitivity to sulphur and hydrogen;

- low structure effect on the response factors of the rays;

- small response linearity area of the hydrogen ray;

- insufficient nitrogen detection limit $^{2}$ to analyse this element present as traces in distillates.

For exemplification purposes, Figure 2 illustrates the response of the AED detector to hydrogen over the 0-30 ng range of injected hydrogen. Taking this small linearity area of the signal into account, a linearisation protocol of the signal is necessary to analyse distillates [5].

\section{TABLE 1}

Response characteristics of the emission rays of carbon, hydrogen, sulphur and nitrogen

\begin{tabular}{c|c|c|c}
\hline $\begin{array}{c}\text { Element and } \\
\text { ray selected }\end{array}$ & $\begin{array}{c}\text { Linear range } \\
\text { in ng injected }\end{array}$ & $\begin{array}{c}\text { Detection } \\
\text { limit pg/s }\end{array}$ & $\begin{array}{c}\text { Linearity } \\
\text { limit pg/s }\end{array}$ \\
\hline $\mathrm{C}^{496 \mathrm{~nm}}$ & $0->200$ & 20 & $>5600$ \\
\hline $\mathrm{H}^{486 \mathrm{~nm}}$ & $0-5$ & 1 & 200 \\
\hline $\mathrm{S}^{181 \mathrm{~nm}}$ & $0-20$ & 2 & 450 \\
\hline $\mathrm{N}^{174 \mathrm{~nm}}$ & $0->200$ & 15 & $>4500$ \\
\hline
\end{tabular}

(2) The new generation of AED detector enables analysing $\mathrm{N}$ with a $388 \mathrm{~nm}$ analytical ray that is far more selective than the $174 \mathrm{~nm}$ one [12].
Figure 2

Response of the $\mathrm{H}^{486} \mathrm{~nm}$ ray of hydrogen over the $0-30 \mathrm{ng}$ range.

\subsection{Analytical Method of Petroleum Distillates by GC-AED}

A middle distillate (gas oil) is composed of a multitude of different hydrocarbon structures and the elementary mass concentrations will fluctuate around $85 \%$ for carbon $14 \%$ for hydrogen, several $\%$ to a few ppm for sulphur and from several hundred to a few ppm for nitrogen. 
The analysis is performed thanks to the emission rays of carbon, hydrogen and sulphur in two injections (first injection: $\mathrm{C}^{496 \mathrm{~nm}}$ and $\mathrm{H}^{486 \mathrm{~nm}}$, second injection: $\mathrm{S}^{181 \mathrm{~nm}}$ ), since the detector can analyse the luminous spectrum emitted only per $50 \mathrm{~nm}$ range.

The sample is first of all diluted in dichloromethane in order to adjust the quantities of elements injected according to the characteristics of the detector described above, whereby the selection of the conditions is guided by the best compromise between sensitivity to minor elements $(\mathrm{S}, \mathrm{N})$, response linearity of hydrogen and plasma stability (see carbon deposits).

From the raw data constituted by the three specific chromatograms $\mathrm{C}, \mathrm{H}$ and $\mathrm{S}$ obtained on a distillate by GC-AED, the results are expressed in the form of three types of information:

- global elementary composition: $\% \mathrm{C}, \% \mathrm{H}, \% \mathrm{~S}$;

- simulated distillation: $\%$ distilled matter $=f$ (boiling temperature) or vice versa;

- elementary composition in distillation profile: $\% \mathrm{C}, \% \mathrm{H}$ or $\% \mathrm{~S}$ per $x \%$ faction of eluted mater $=f$ (boiling temperature) or still, $\mathrm{H} / \mathrm{C}$ and $\mathrm{S} / \mathrm{C}$ atomic ratios per $x \%$ section of eluted matter $=f$ (boiling temperature).

Calibrating the C-H-S composition calculation is made from the analysis of solutions of a diterbutyldisulphur standard. The retention times are calibrated in relation to the boiling temperature as in conventional simulated distillation from the injection of a mixture of $n$-paraffins.

\section{VALIDATION OF THE GLOBAL ELEMENTARY ANALYSIS AND IN BOILING TEMPERATURE PROFILE OF THE DISTILLATES}

\subsection{Experimental Methodology}

The sample basis on which we have worked is composed of some fifty atmospheric kerosene and gas oil distillates. Let us bear in mind that the kerosene and gas oil cuts are defined by boiling temperature intervals of $150-250^{\circ}$ and $150-400^{\circ} \mathrm{C}$, respectively. The basis samples are representative of straight run distillates from crude oils of various origins and from most distillates derived from diverse refining processes (catalytic cracking, viscoreduction, hydrotreating, etc.).

The methodology used to validate the analysis of the distillates by GC-AED has consisted in assessing the precision and the bias of the method for each of the three types of information supplied: global C-H-S analysis, simulated distillation and $\mathrm{C}-\mathrm{H}-\mathrm{S}$ composition profiles in relation to distillation.

Precision has been assessed in intralaboratory reproducibility conditions, i.e. the analyses have been repeated over several weeks the better to take time-related experimental fluctuations as well as the effect of different calibrations into account. Two distillates, selected because of their very different structure, were used for the measurements, a highly hydrotreated low aromatic gas oil (GO HDT) and a highly aromatic catalytic cracking gas oil (LCO).

Bias has been assessed while comparing the results of the GC-AED to those obtained using methods considered as reference methods.

The results of global elementary analysis of the whole distillate base have been compared to the results of elementary analysis of the global reference methods practised at IFP.

The simulated distillation profiles of distillates representative of the base have been compared to those obtained by conventional simulated distillation and by standardised physical distillation.

The composition profiles of distillates representative of the base have been compared to the profiles obtained by elementary analysis of narrow cuts derived from preparative physical distillation of the said distillates.

Preparative distillation of the selected samples has been prepared according to the method ASTM D2892 [6], whereby the narrow cuts are centred on the temperature of normal paraffin long the distillation curve. Very good agreement between global elementary analysis and that recalculated from the throughput and elementary analysis of each narrow cut has enables validation of the $\mathrm{C}, \mathrm{H}, \mathrm{S}$ reference profiles obtained by physical distillation.

On each cut, besides elementary analyses, certain petroleum determinations, such as density, refraction index, cetane number, etc., have been conducted according to the ASTM methods in order to validate the property profiles calculated by correlation.

\subsection{Global Elementary Analysis}

\subsubsection{Precision}

The results of intralaboratory reproducibility study of global elementary analyses are reported at Table 2 .

TABLE 2

Intralaboraty reproducibility of C-H-S elementary analysis

\begin{tabular}{l|c|c|c}
\hline Element & $\begin{array}{c}\text { Mean } m \\
\text { (\%weight) }\end{array}$ & $\begin{array}{c}\text { Reproducibility } \\
\text { Standard deviation } \\
\mathrm{S}_{R L} \text { (\%weight) }\end{array}$ & $\begin{array}{c}\text { Reproducibility } \\
R_{L}=2.8 \mathrm{~S}_{R L} \\
\text { (\%weight) }\end{array}$ \\
\hline \multicolumn{4}{c}{ Highly hydrotreated gas oil (GO HDT) } \\
\hline Carbon & 85.73 & 0.19 & 0.53 \\
Hydrogen & 14.27 & 0.19 & 0.53 \\
Sulphur & - & - & - \\
\hline \multicolumn{4}{c}{ Catalytic cracking gas oil (LCO) } \\
\hline Carbon & 88.71 & 0.24 & 0.67 \\
Hydrogen & 10.68 & 0.22 & 0.63 \\
Sulphur & 0.61 & 0.02 & 0.06 \\
\hline
\end{tabular}


For carbon and hydrogen, the standard deviation of intralaboratory reproducibility is assessed at approximately $0.2 \%$ weight over the concentration range of distillates. The type of distillate does not seem to play a part. An isolated result of analysis will therefore exhibit a confidence interval (with $95 \%$ probability) of more or less $0.4 \%$ weight, i.e. a relative error of approximately $0.5 \%$ on carbon and $3 \%$ on hydrogen. For sulphur, the confidence interval of an isolated result is estimated at more or less $0.04 \%$ which represents a relative error of approximately 7 for $0.6 \%$ weight.

Intralaboratory reproducibility of determination of total hydrogen by GC-AED, equal to $0.6 \%$ weight, should be compared to that of other methods. The combustion method ASTM D1018 [7] specifies repeatability and reproducibility values of 0.11 and $0.18 \%$ weight, respectively at this level of concentration. The NMR hydrogen method developed by IFP, [12] shows a repeatability of approximately $0.05 \%$ weight. It can thus be noted that determination of hydrogen by GC-AED is less accurate, which is not astonishing taking into account the complexity of the processes involved and the quantitative approach used for hydrogen. The purpose of the GC-AED method is however not to provide a global analysis.

Intralaboratory reproducibility of determination of total sulphur by GC-AED is equal to $0.06 \%$, i.e. $10 \%$ of the content analysed for $0.6 \%$. From an informative viewpoint, the wavelength dispersing X-ray fluorescence method ASTM D2622 [8] provides a repeatability equal to $5 \%$ and a $10 \%$ reproducibility of the sulphur content from 0.15 to $5 \%$ weight, which is rather comparable.

\subsubsection{Bias}

Accuracy has been assessed while comparing the GC-AED results obtained on 78 samples of the distillate base whose results were supplied by the methods used at IFP and considered here as reference methods: hydrogen by low resolution NMR [12], sulphur by wavelength dispersing X-ray fluorescence (ASTM D2622) [8] and carbon calculated by $100 \%$ difference from elementary reference analyses.

For the three elements, the ordinate at the origin was found statistically equal to 0 and the test was repeated on the regression $y=a z$ (with $n^{-1}$ degree of freedom). The statistic parameters are specified at Table 3 and, for exemplification purposes, the $\mathrm{H}$ parity line by GC-AED in relation to $\mathrm{H}$ by NMR has been plotted and represented in Figure 3.

The results show that on the field of concentrations covered, the GC-AED method does not exhibit any bias for carbon and hydrogen determinations: the slopes of the regression lines are equivalent to 1 .

In the case of sulphur, the GC-AED values are above those of X-ray fluorescence; positive proportional bias can be observed on relative approximately $10 \%$-contents. The slope value $a$, equal to 1.1 , is significant. This slight bias could be ascribed to an overestimated response coefficient of sulphur in the calibration protocol.
TABLE 3

Statistic parameters of regression lines $(y=a z+b)$ between $\mathrm{C}-\mathrm{H}-\mathrm{S}$ global analyses in GC-AED $(y)$ and the reference methods $(z)$

\begin{tabular}{l|c|c|c}
\hline & Carbon & Hydrogen & Sulphur \\
\hline $\begin{array}{l}\text { Slope }(\mathrm{Sa}) \\
1.098\end{array}$ & & 0.9995 & 1.0007 \\
\hline Standard deviation of $\mathrm{Sa}$ & 0.0004 & 0.0024 & 0.0086 \\
\hline Degrees of freedom & 77 & 77 & 77 \\
\hline Residual standard deviation & 0.28 & 0.28 & 0.08 \\
\hline Correlation coefficient & 0.953 & 0.955 & 0.993 \\
\hline
\end{tabular}

$* b$ : the ordinate at the origin has been assessed statistically as equal to 0 .

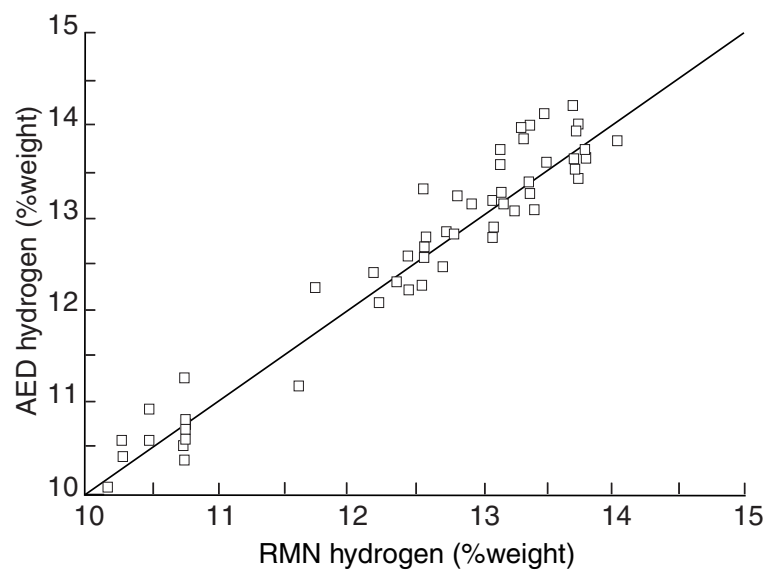

Figure 3

Comparison of GC-AED and H RMN hydrogen global analysis results.

\subsection{C-H-S Elementary Analysis in Distillation Profile}

\subsubsection{Precision}

Intralaboratory reproducibility has been assessed on composition profiles of narrow matter cuts equal to $2 \%$ weight of the distilled product, from the GC-AED analyses of GO HDT and LCO distillates whose chromatograms are represented on Figures 4 and 5 respectively. The trend of $\mathrm{H}$ profiles obtained after calculations is illustrated on Figures 6 to 7 , on which the GC-AED simulated distillation curve as well as the analysis profile of narrow cuts of each sample have also been indicated. Elementary composition of given $2 \%$ weight cuts of the distilled product has been compared ${ }^{3}$ (for example, between 48 and 50\% distilled weights).

(3) From one cut to another. 

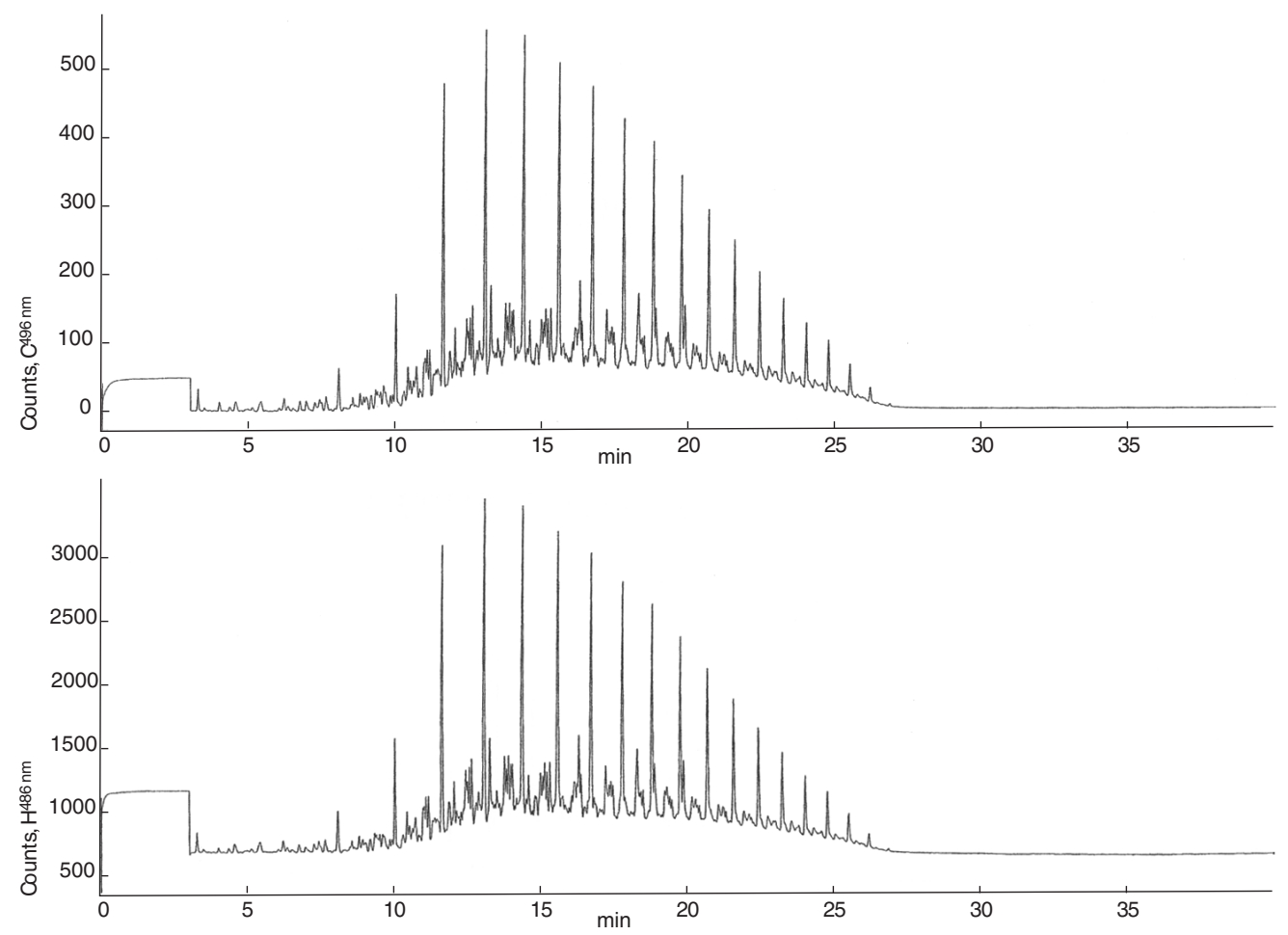

Figure 4

$\mathrm{C}$ and $\mathrm{H}$ chromatograms of GO HDT.
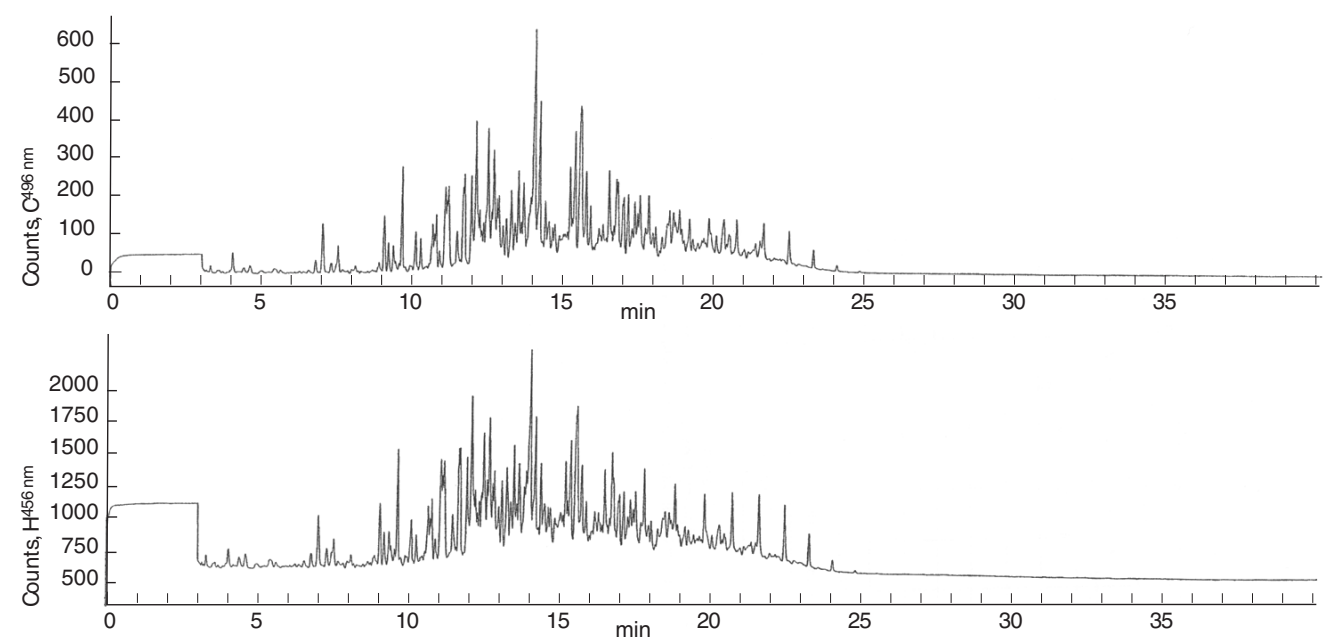

Figure 5

$\mathrm{C}, \mathrm{H}$ and $\mathrm{S}$ chromatograms of LCO.

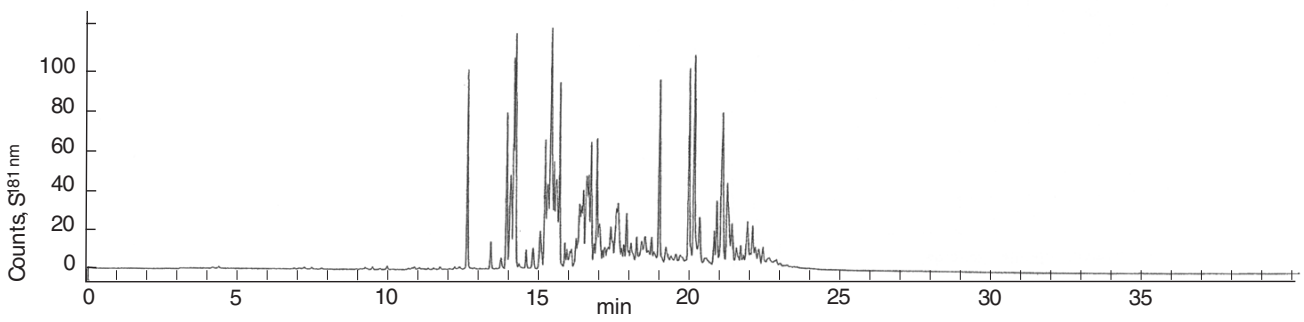




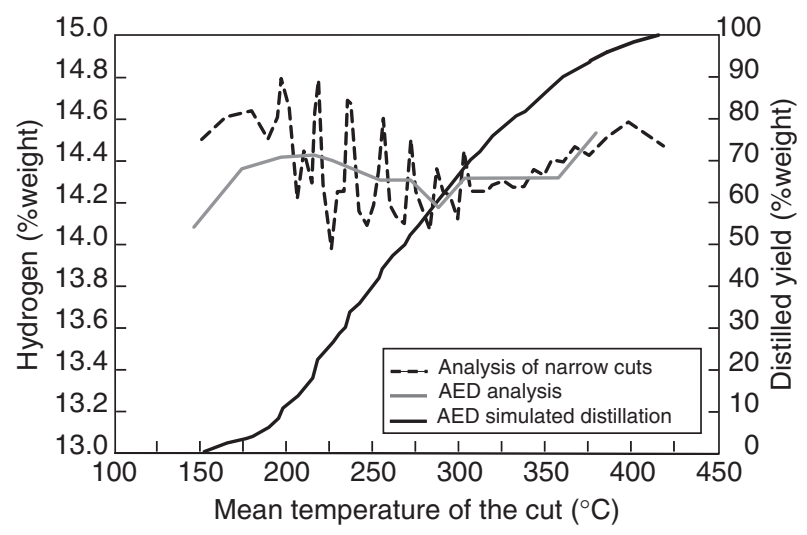

Figure 6

Average hydrogen profile of GO HDT elementary analysis every $2 \%$ matter.

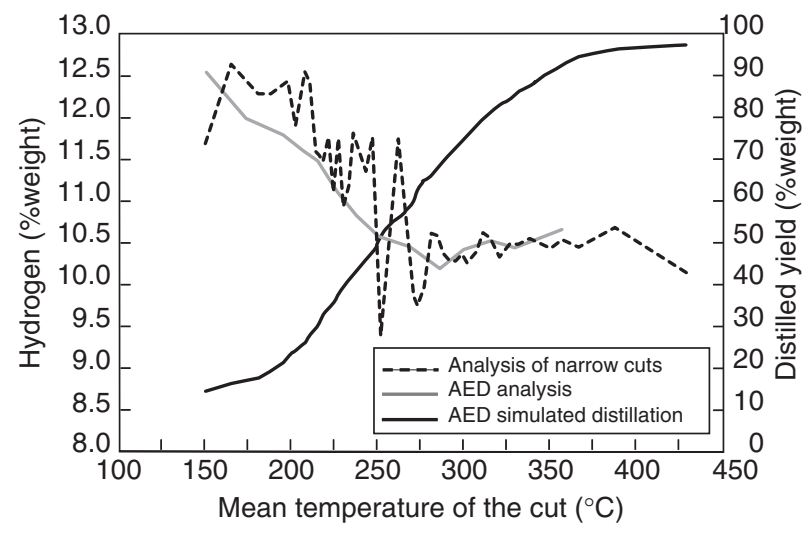

Figure 7

Mean hydrogen profile of LCO elementary analysis every $2 \%$ matter.

In the case of the GO HDT, the values of standard deviations SRL for carbon and hydrogen vary little from one cut to another and are comparable to those observed for global analysis $(0.2 \%$ weight). On the other hand, important fluctuations can be observed in the case of LCO with SRL values ranging from 0.2 to $0.8 \%$ for carbon and hydrogen, and also for sulphur.

Variability of C-H-S analyses in distillation profile can be explained by the structure of the distillates and the calculation mode implemented for elementary profile analysis. Indeed, the GO HDT that does not contain any sulphur, is a gas oil ${ }^{4}$. Hydrogen content of the cuts averages $14.36 \%$ with a $0.2 \%$ standard deviation from one cut to another. The compositions along the distillation profile are rather little sensitive to the offsets of the cuts from one analysis to another. On the other hand, the profile composition of LCO is far more variable. Hydrogen content of cuts on LCO averages $10.82 \%$ with a $1 \%$

(4) On which the C-H composition of each cut of $2 \%$ remains relatively stable.

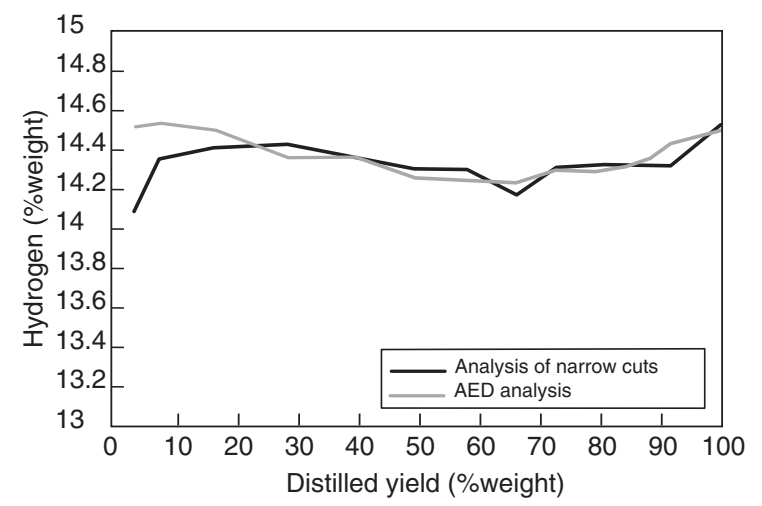

Figure 8

standard deviation from one cut to another. Small position offset of a cut of $2 \%$ distilled compounds on $\mathrm{C}, \mathrm{H}$ and $\mathrm{S}$ chromatograms causes this time significant variation in composition of the latter. It is therefore preferable not to oversample a composition profile: the precision of cut-based analysis is better when the width (in \% distilled compounds) of the cuts is increased. The general trend of the profile can however be traced from one analysis to another, whereas the integral lies in the precision of the global analysis described at the previous paragraph.

\subsubsection{Bias}

For distilled samples in a few \% weight narrow cuts (10 to 15 cuts per sample), we have determined from the yields of preparative distillation, the cuts of $\%$ distilled compounds on the GC-AED profile corresponding to the different narrow cuts. C-H-S analyses of these cuts of the GC-AED profile have then been cumulated to enable us comparing for a given distillation isoyield, the results with the elementary analyses of narrow cuts.

Profile comparisons of isoyield hydrogen content between GC-AED and preparative distillation. 
Figure 8 enables to visualise this comparison of the analyses of the narrow cuts with GC-AED profiles recalculated for a given distillation yield in the case of GO HT samples (hydrogen profile) and LCO (hydrogen and sulphur profiles). Elementary profile analyses by GC-AED agree perfectly with narrow cut analysis.

In order to quantify possible biases, the approach used for global analyses was applied to the analysis of narrow cuts. Examination of the regression parameters shows that the results are statistically equivalent in the case of carbon and hydrogen analysis. We have an approximately $10 \%$ relative bias on sulphur as already observed in global analysis.

\section{APPLICATION TO THE STUDY}

It is interesting to try and locate the GC-AED coupling among the set of techniques available to characterise petroleum distillates.

The GC-AED coupling exhibits first of all an economic interest because as, in a single analysis, we determine the global elementary composition (C-H-S) and the simulated distillation curve. The results show that the analysis precision and the detection limit of sulphur and of nitrogen should be improved so that GC-AED coupling could replace traditional techniques. GC-AED still remains a quick valuation tool of the distillate database.

It can also be used to characterise sulphured compounds, for example to identify thiophenic sulphurs refractory to hydrotreating and provide the distribution of sulphur in distillation profile (simulated distillation of sulphur). We shall not develop here this type of application, which is described within the framework of a specific study [9], while using a specific chemiluminescence chromatographic detector of sulphur, which exhibits similar performances to that of GC-AED. The new generation of GC-AED can also be contemplated to identify nitrogen compounds, whereby this piece of information is already accessible by other (chemiluminescence, NPD) specific nitrogen detectors.

In fact, the originality of GC-AED coupling lies in that it is multi-elementary and the unique chromatographic detector capable of analysing hydrogen specifically, thus giving access to elementary composition in distillation profile. GCAED thus constitutes with GC-MS (mass spectrometer) coupling, one of the rare techniques enabling to obtain information on the composition of distillates in relation to their distillation profile. It should be noted that the nature of information that can be obtained by one technique or the other is very different. GS-MS gives very rich structural profile information, useful for example for kinetic and reaction studies in refining processes. But the methods developed for quantitative analysis in distillation profile are limited to atmospheric distillates and their implementation is time consuming since prior fractionating of the distillate by liquid chromatography is necessary $[10,11]$. For its own part,
GC-AED provides more readily accessible information on a routine basis and which could be extended to distillates heavier than gas oils. Consequently, datas are less informative.

What can the knowledge of elementary composition in distillation profile bring to distillate characterisation? In reply to this question, we shall describe below two examples of use of GC-AED composition profiles: classifying distillates of various origins and predicting, using correlations, properties in relation to the distillation profile. For this latter point, the cetane number, which is one of the most important properties of gas oils, has been selected, whereby the methodology can be extended to other types of petroleum properties.

\subsection{Classification of Distillates - Typology of Elementary Profiles}

The study conducted on our distillate base shows that there are typical composition profiles in relation to the origin (process) of the distillates, whereby the profile exhibit structural characteristics in spite of indetermination associated with the mean structural information provided by elementary composition. This profile typology, whose criteria can be refined from the analysis of a great variety of distillates, suggests that GC-AED can be a fast way to classify the distillates in relation to their properties per type, possibly their reactivity per type in certain processes. For exemplification purposes, the $\mathrm{H} / \mathrm{C}$ atomic profiles in relation to the boiling temperature of certain types of distillates are represented on Figures 9 to 14.

\subsubsection{Hydrotreated Distillates}

This group is composed of very hydrogenated distillates derived from hydrotreating and hydrocracking processes. They contain fewer than $10 \%$ aromatic compounds as well as traces of sulphur and nitrogen. The $\mathrm{H} / \mathrm{C}$ profiles enable differentiating the products of the various processes.

\section{GO HDT (Fig. 9)}

Hydrotreated gas oils (HDT) have an average H/C ratio of more or less constant value between 1.9 and 2 along the distillation profile and peaks due the contribution of normal paraffins can be observed.

Gas oil hydrotreating processes eliminate sulphured and nitrogenated compounds while hydrogenating a major section of the aromatic into naphthenic compounds, practically without any conversion. The paraffins present in the feedstocks before hydrotreating can still be found. These $\mathrm{H} / \mathrm{C}$ profiles should be compared to those of straight run gas oils, also containing approximately $40 \%$ paraffins (Fig. 11).

\section{GO HDC and HDR (Fig. 10)}

The H/C profiles of these gas oils are situated between 1.9 and 2 and have the particularity of being little prone to fluctuations or peaks due to normal paraffins. They reflect the particular structure of hydrocracking gas oils containing a 


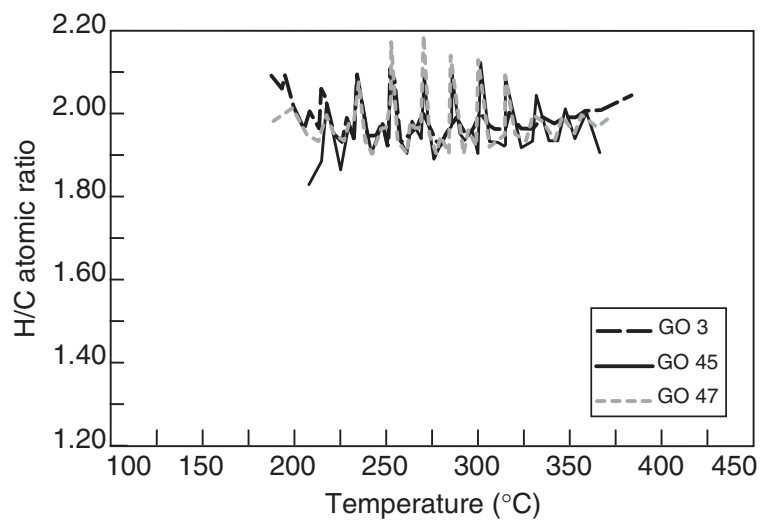

Figure 9

$\mathrm{H} / \mathrm{C}$ ratio in distillation profile of hydrotreated gas oils.

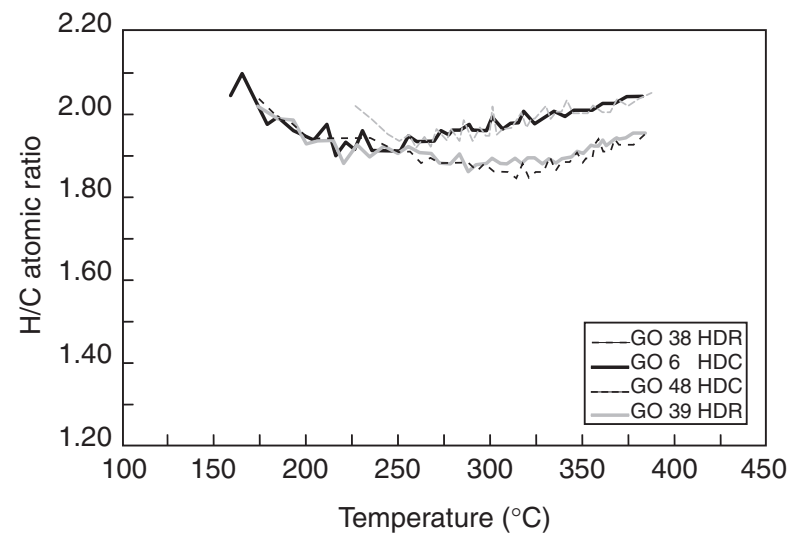

Figure 10

$\mathrm{H} / \mathrm{C}$ ratio in distillation profile of hydrocracking (HDC) and hydrorefining (HDR) gas oils. lot of naphthenic compounds and isoparaffins, formed by the cracking of the heavier compounds present in the vacuum distillate feedstock.

Hydrorefining gas oils (HDR) are distinguished by the $\mathrm{H} / \mathrm{C}$ level that remains close to 1.9 above $250^{\circ} \mathrm{C}$, whereas that of hydrocracking gas oils (HDC) increases towards 2 (limit value of a mixture of approximately $40 \% n$ and isoparaffins and $60 \%$ of a majority of one-ring naphthenes).

Indeed, whereas in conventional hydrocracking the purpose is to maximise the formation of distillates, hydrorefining is a deep hydrotreating process without cracking, designed for preparing quality base oil residues. We obtain more naphthenes in HDR gas oils and the latter are more condensed.

\subsubsection{Straight Run Distillates}

As regards straight run gas oils, we have not put in evidence, from our sample base, any $\mathrm{H} / \mathrm{C}$ profile nor $\mathrm{S}$ profile truly representative taking the diversity of origin of crude oils into account.

The H/C profiles cover a wide variation area as illustrated on Figures 11 and 12. As this study is not conducted within the framework of a geochemical context, we have simply splitted the H/C profiles from the SR distillates into two major types according to paraffin content. This presentation is far more judicious than that based on the basic criterion of the refiner, aromaticity, by reason of indetermination of the naphthene-aromatic contributions to the $\mathrm{H} / \mathrm{C}$ ratio: it is the sum of the naphthene and aromatic contributions which determines the type of $\mathrm{H} / \mathrm{C}$ profile and its level of values and not the aromatic content. Only a more comprehensive study could enable to define finer classification criteria from the complete GC-AED data.

\section{Paraffin SR GO (Fig. 11)}

The presence of $n$-paraffins in large quantity can be distinguished easily on an $\mathrm{H} / \mathrm{C}$ profile by the regularly spaced peaks as outlined in the case of the HDT GO. The $\mathrm{H} / \mathrm{C}$ value decreases by approximately 2 , to $1.8-1.7$, whereas the variation is more accentuated between 200 and $300^{\circ} \mathrm{C}$. This evolution can be explained by the increase in the total aromatic content and in condensed naphthenic cycles 5 , caused by the rising boiling temperature ${ }^{6}$, whose contribution to the reduction in the $\mathrm{H} / \mathrm{C}$ ratio decreases gradually when the number of carbons increases in the molecules, due to the increase of alkyl side chains.

\section{Naphtheno-aromatic SR GO (Fig. 12)}

The profiles underline the contribution of $n$-paraffins to a lesser extent, the $\mathrm{H} / \mathrm{C}$ value falls from 1.9 to 1.7 between 200 and $275^{\circ} \mathrm{C}$ and remains quite close to that level afterwards (up to $400^{\circ} \mathrm{C}$ ). This small evolution is probably due as previously, to the compensation effects.

\subsubsection{Catalytic Cracking Distillates}

These distillates (LCO) are distinguished by their aromatic content, which is greater than $70 \%$ and by the fact that they only contain thiophenic sulphured compounds. They exhibit very characteristic $\mathrm{H} / \mathrm{C}$ and $\mathrm{S}$ profiles at the same time.

The H/C profiles (Fig. 13) exhibit a significant decrease with an average value falling from approximately 1.8 to 1.3 between 200 and $275^{\circ} \mathrm{C}$ ( $n=11$ to 15$)$, then remain more or less constant. A major oscillation can be observed around these average values, linked to the distribution of the aromatic group-types in presence. Such a low H/C level as of $250^{\circ} \mathrm{C}$ can be explained by the occurrence of a major quantity of diaromatic compounds which are added to the contribution of the monoaromatic compounds as can be seen by a GC-MS analysis. As regards higher final boiling point $\mathrm{LCO}$, the $\mathrm{H} / \mathrm{C}$ ratio picks up beyond $350^{\circ} \mathrm{C}$ and peaks can be noted, linked to the presence of paraffins.

(5) Up to $300^{\circ} \mathrm{C}$

(6) When above $300^{\circ} \mathrm{C}$. 


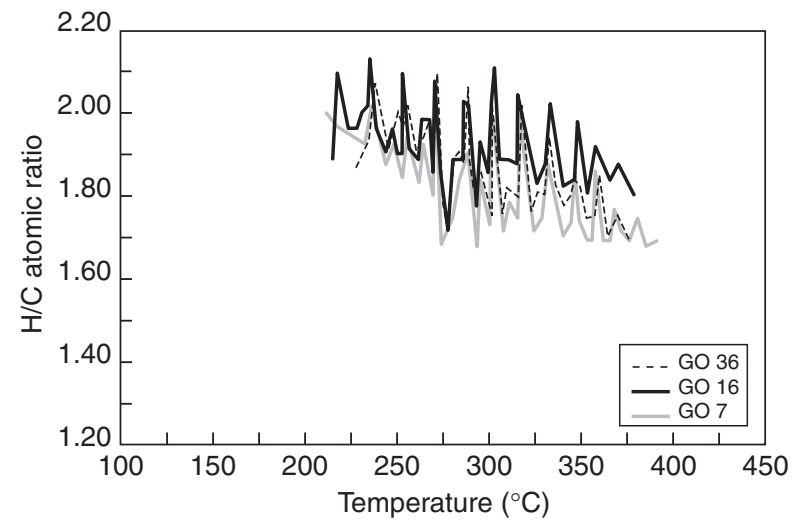

Figure 11

$\mathrm{H} / \mathrm{C}$ ratio in distillation profile of paraffinic atmospheric distillation (SR) gas oils.

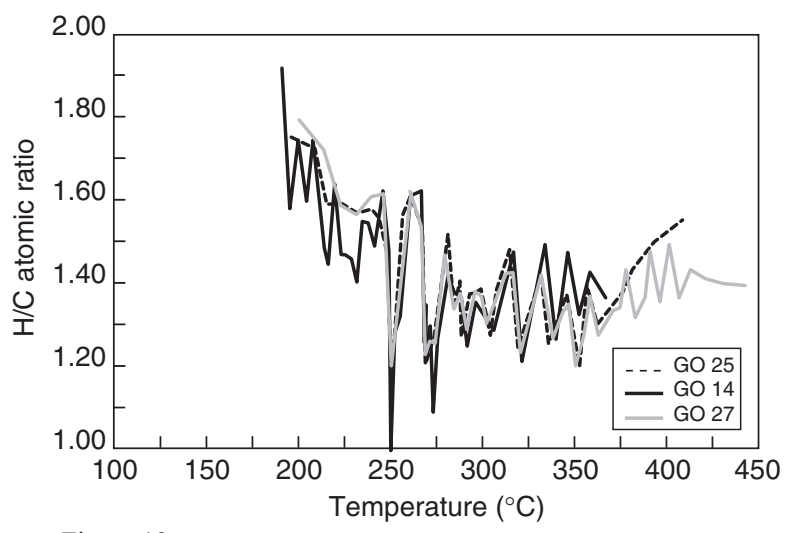

Figure 13

$\mathrm{H} / \mathrm{C}$ ratio in distillation profile of catalytic cracking (LCO) gas oils.

The S profiles (Fig. 14) can be noticed, whatever the global sulphur content, by the presence of peaks distributed over two blocks corresponding to the group-types of alkylbenzothiophene compounds (between 225 and $325^{\circ} \mathrm{C}$ ) andaklyl-dibenzothiophene compounds $\left(>325^{\circ} \mathrm{C}\right)$. They can be identified more in detail on a specific chromatogram of sulphur obtained with a better resolution as we have shown in a previous study [9].

\subsection{Prediction of Petroleum Properties in Distillation Profile; Example of the Cetane Index}

Studying the evolution of the petroleum properties of a distillate in relation of its boiling temperature generally calls for preparative distillation of the product into different cuts, followed by the analysis of the properties of each of these fractions. For example, to obtain the cetane number in distillation profile, we must determine the cetane number of each cut according to the method ASTM D613 (CFR engine)

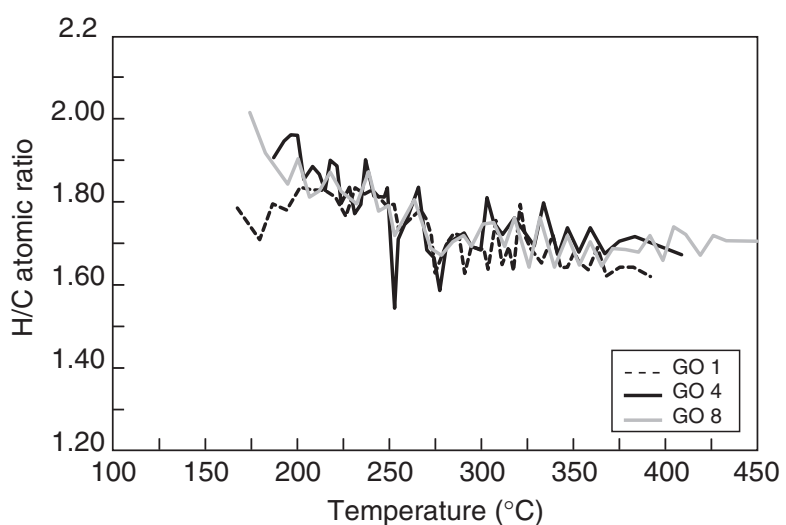

Figure 12

$\mathrm{H} / \mathrm{C}$ ratio in distillation profile of naphtheno-aromatic straight run (SR) gas oils.

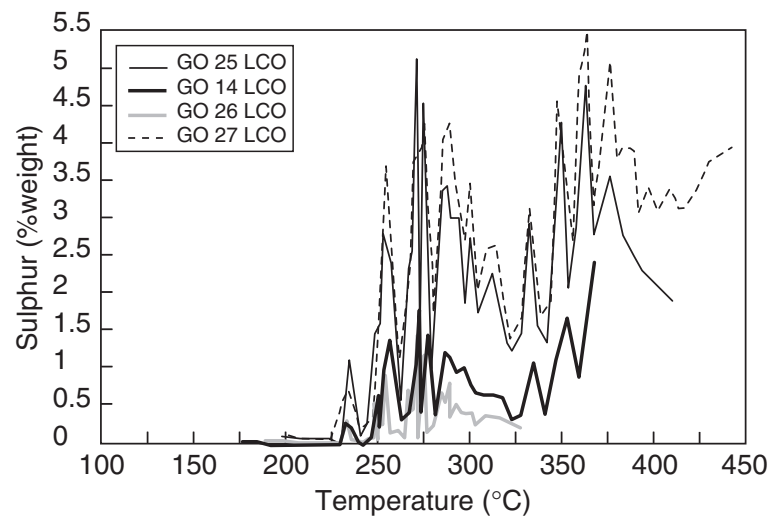

Figure 14

$\mathrm{S}$ content in distillation profile of catalytic cracking (LCO) gas oils.
[13]. The cost of the property profiles is therefore very high and a few studies are carried out on a routine basis.

We will show below that it is possible to use GC-AED information composed of the $\mathrm{H} / \mathrm{C}$ ratio and boiling temperature along the distillation curve, in order to predict the profile of the properties linked to the average structure of the distillates. Indeed, as a first approximation, the $\mathrm{H} / \mathrm{C}$ ratio can be correlated to the aromaticity and the boiling temperature to the average molecular mass of a cut of $x \%$ distilled, and the distribution of the value couples is characteristic of the structure of the distillate (see typology). The methodology adopted has consisted in establishing a global predictive model combining the property (for instance, cetane number) to the $\mathrm{H} / \mathrm{C}$ ratio and the average boiling temperature $(T)$ of the distillates considered and in applying the said model to the distributions $(\mathrm{H} / \mathrm{C}, T)$. The model was validated at global level and along the distillation profiles as for the validation of elementary analyses, by comparison with the standardised measurements taken from the cuts of preparative distillation. 
Figure 15 shows the parity diagram between the value of cetane index calculated from GC-AED analyses and that of the CFR engine cetane number (ASTM D613) [13] over all the products of our atmospheric distillate base. The residual standard deviation is approximately 3 -point cetane. We have not sought to improve the quality of prediction to the calculation level (parameters of the model) on the one hand, so as not to affect the robustness of the model and, on the other, because we think that a major improvement axis regards first of all the repeatability of GC-AED analyses on the new generation equipment.

Figures 16 to 19 represent, for a few distillates, the cetane profiles measured on the narrow cuts and those calculated on the basis of GC-AED analyses. Very good agreement between measurements and predictions can be noted. Let us bear in mind that the oscillations of the GC-AED profile with respect to that of the measurements on the distillation cuts can be ascribed to the variations in sampling along the distillation sections of a few $\%$ in preparative distillation.

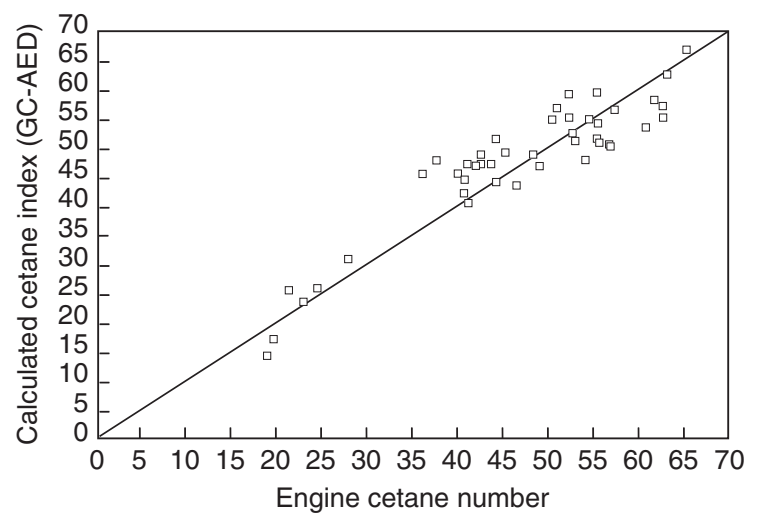

Figure 15

Comparison between engine cetane number and calculated index from GC-AED analyses.

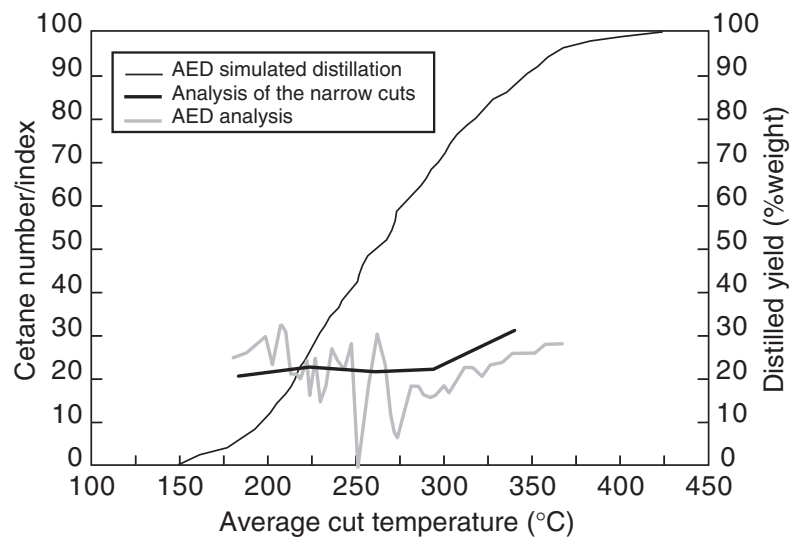

Figure 16

Cetane profile of a catalytic cracking gas oil.

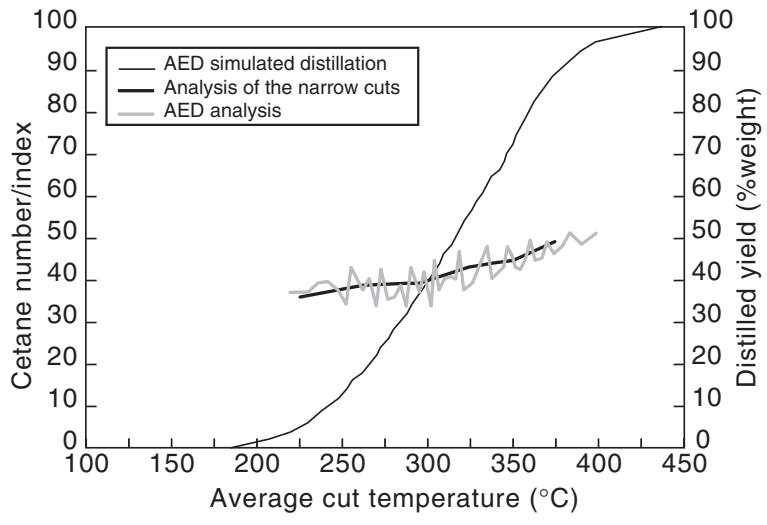

Figure 17

Cetane profile of hydrodemetallation gas oil.

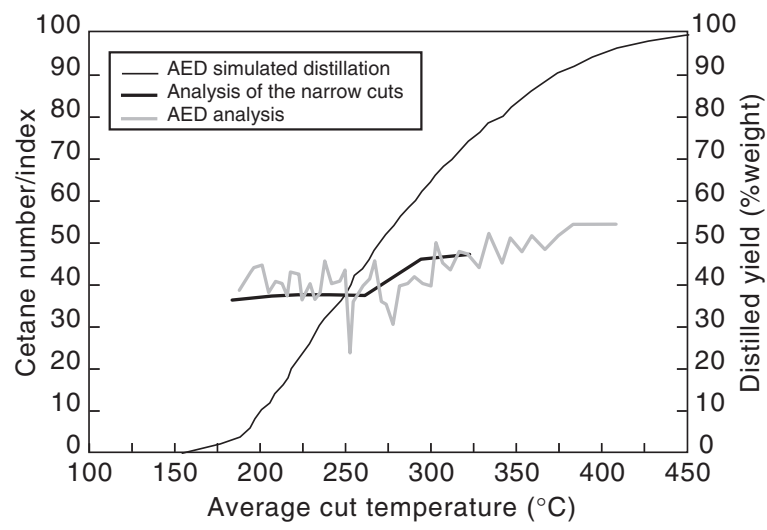

Figure 18

Cetane profile of a straight run gas oil.

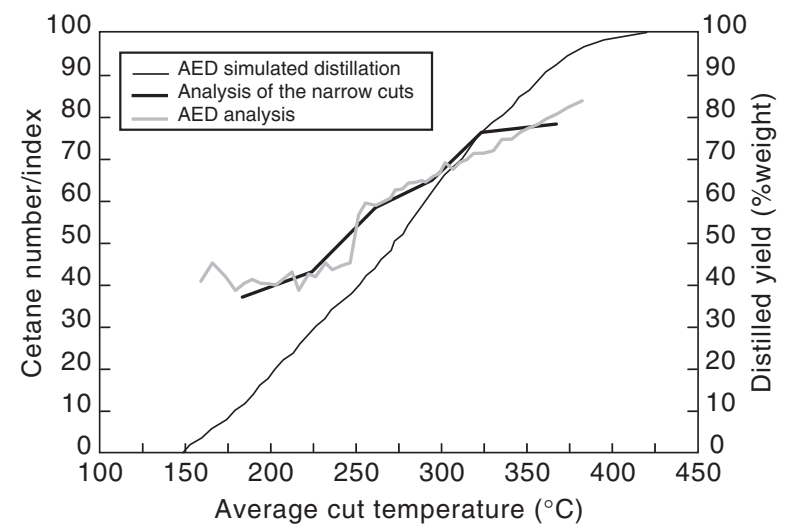

Figure 19

Cetane profile of a hydrocracking gas oil. 
Examining all the cetane profiles calculated by GC-AED on the basis of samples has enabled us quickly to pinpoint a typology of the cetane profiles, in particular in relation to the origin process of distillates. As we can observe:

- An increase of the cetane in relation to the boiling temperature. This reflects the known tendency linked to the evolution of the length of the paraffin chains, the increase of the molecular mass.

- An initial level and a slope which is more or less steep according to the type of distillate. In particular the slope of the cetane profile becomes smoother as the product contains more aromatic compounds (example, Fig. 16, catalytic cracking gas oil), i.e. steeper as the product is hydrogenated.

The distillates derived from hydrocracking (Fig. 19) and hydrorefining with much steeper slopes and a lower initial cetane level than certain less hydrogenated products can be distinguished from hydrorefining products. As these distillates are very naphthenic and contain many more isoparaffins taking the nature of the process into account, this observation suggests that the length of the substituted alkyle chains increases rapidly with the molecular mass of the compounds.

This type of information readily available on a routine basis could be used to modulate the cetane index of a distillate in relation to its distillation interval. The approach is applicable, a priori, to any other property linked to the average structure of the distillates. The limits reside in the accuracy of the GC-AED analysis and the quality of predictive models.

\section{CONCLUSION}

The purpose of this study was to investigate the performances of a relatively recent technique applied to analysis of petroleum distillates, gas phase chromatographyatomic emission spectrometry (GC-AED) coupling and to assess its potential contribution to better characterisation of these complex hydrocarbon mixtures.

We have determined the intrinsic performances of the detector in comparison to the main elements present in the distillates, carbon, hydrogen, sulphur and nitrogen. This has enabled us to optimise an analytical method giving simultaneous access to three types of information on distillates: global elementary composition, chromatography-simulated distillation curve and, which is more unusual, elementary composition profile in relation to distillation. The precision of the GC-AED analytical method of distillates (precision and bias) has been assessed for the three types of information. This study was carried out while using a sample base of distillates representative of the various refining processes and hence of the various types of composition and structure.

The relevancy of the GC-AED coupling for characterisation of petroleum distillates has been covered at several levels, while situating it with respect to the other techniques. We have focussed on the observation that GC-AED is one of the rare techniques enabling to describe the average composition of distillates in relation to their distillation profiles and that the information is easier to obtain and to validate than that of GC-MS coupling. Consequently, the GC-AED information is relatively poor in comparison to that of the GC-MS: elementary composition in profile, per increment of the percentage of distilled matter, remains an average structural information in the case of so complex mixtures and only a fraction of the indetermination is eliminated. Potential applications have been illustrated using a few examples.

In the case of atmospheric distillates, the elementary composition profiles obtained constitute a set of data that is relatively new at the scale of variegated sample base and we have been able to outline a typology of the profiles in relation to the characteristics or the origin (refining process) of the distillates. This typology opens up perspective for rapid classification of the distillates per representative property, possibly per reactivity in certain processes. Using the example of the cetane number, which is one of the major properties of gas, oils, we have also shown that it was feasible to predict the evolution in relation to the distillation profile, of properties linked to the average structure of the distillates. This application is particularly useful to optimise the distillation intervals of the petroleum cuts in relation to the specifications contemplated, and to analyse more in detail the effect of operating conditions on the effluent quality of a given process.

The field of possible applications is certainly not limited to the sole domain of petroleum refining. The technique is applicable to vacuum distillates and should be extended to heavier products. From an analytical viewpoint and in analogy to the development of simulated high temperature distillation, the perspective to obtain on a routine basis a profile information on composition and the average structure of distillable fractions up to $750^{\circ} \mathrm{C}$, sets to GC-AED its best challenge.

\section{REFERENCES}

1 Quimby, B.D. and Sullivan, J.J. (1990) Analytical Chemistry, 62, 1027.

2 Sullivan, J.J. and Quimby, B.D. (1989) Journal of High Resolution Chromatography, 12, 282.

3 Wylie, P.L. and Quimby, B.D. (1989) Journal of High Resolution Chromatography, 12, 813.

4 Quimby, B.D. and Sullivan, J.J. (1990) Analytical Chemistry, 62, 1034.

5 Baco, F. (1997) Characterisation of Petroleum Distillates by Gas Phase Chromatography and Atomic Emission Detection Coupling. Thesis, Claude Bernard University, Lyon I.

6 ASTM D2892 (1999) Annual Book of ASTM Standards. 05-02, 220-246. 
7 ASTM D1018 (1996) Annual Book of ASTM Standards, 05-01, 353-357

8 ASTM D2622 (1999) Annual Book of ASTM Standards, 05-02, 20-32/.

9 Baco, F. (1993) Analysis of Sulphured Compounds in Gas Oils and their Gas Phase Chromatography-Hydrotreated Effluents. Use of specific detectors. Post-graduate Diploma in Analytical Chemistry. Claude Bernard University, Lyon I. CNAM Engineer Dissertation, Lyon 1994.

10 Magne-Drisch, J. (1995) Kinetic of Distillate Reactions to Hydrotreating Processes by Breakdown into Group-Types and Narrow Cuts. Thesis, Pierre et Marie Curie University, Paris VI.
11 Fafet, A. and Magne-Drisch, J. (1995) Detailed Quantitative Analysis of Middle Distillates by GC-MS Coupling. IFP Bulletin, May-June, 50, 3.

12 Gauthier, S. and Quignard, A. (1995) Low resolution 1H nuclear magnetic resonance-The best tool for accurate determination of hydrogen content of petroleum products. IFP Bulletin, March-April , 50, 2.

13 ASTM D163 (1999) Annual Books of ASTM Standards, 05-04, 1-28. 